\title{
EL PROTAGONISTA Y EL HÉROE: DEFINICIÓN Y ANÁLISIS POÉTICO DE LA ACCIÓN DRAMÁTICA Y DE LA CUALIDAD DE LO HEROICO
}

\author{
Ruth Gutiérrez Delgado \\ (Universidad de Navarra) \\ rgutierrez@unav.es
}

\begin{abstract}
Resumen: En este artículo se distinguen los conceptos de protagonista y héroe, desde la perspectiva dramática. Esta distinción resulta fundamental como base para el análisis del heroísmo y su función en la ficción cinematográfica. Asimismo, este trabajo supone una revisión crítica del paradigma tradicional del viaje y del ciclo mítico heroico divulgado por Christopher Vogler y Northrop Frye, entre otros, en las teorías cinematográfica y literaria. Las dos premisas que sostienen esta distinción son las siguientes: la comprensión del drama fílmico como una única acción, en sentido estricto, y la definición de lo heroico, principalmente como una cualidad y no sólo como una función narrativa o un fenómeno cultural.
\end{abstract}

Palabras clave: Ficción, protagonista, héroe, acción única, cualidad de lo heroico.

Abstract: This article aims to analyze the differences between the terms main character and hero, from a dramatic viewpoint. This distinction is a crucial one as a basis for studying heroism and its function in fiction. The study presents a critical review of the traditional and mythical paradigm of the hero's journey as Christopher Vogler and Northrop Frye have analysed it in film theory. The two main premises which contain this distinction are the following: understanding film drama as only one action, in strictu sensu, and, the definition of the heroic not only as a narrative function but primarily as a dramatic quality or a cultural phenomenon.

Keywords: fiction, main character, hero, only one action, heroic as a quality 
44 El protagonista y el héroe: definición y análisis poético de la acción dramática

y de la cualidad de lo heroico

\section{INTRODUCCIÓN}

a figura del héroe ha suscitado tradicionalmente un interés profundo desde las disciplinas humanísticas. Sin dejar de percibirse el calado de su com- prensión en materia moral, su estudio también se ha ampliado al campo de la cultura, proclamando así la popularidad del héroe en todas y cada una de las manifestaciones artísticas. Como emblema y signo, el héroe sirve de hoja de ruta antropológica para el rastreo del origen y el conocimiento de los hábitos sociales de las civilizaciones (Rose, 1960: 1-8; Bowra, 1964; Nagy, 2001; Lasso de la Vega,1962: 9-11).

En lo que respecta al análisis de la figura del héroe en el cine, como medio dramático de comunicación de masas, la identificación constante entre el protagonista del relato y el héroe ha generado una variada tipología heroica, poniendo de manifiesto los abundantes cambios culturales a los que se somete la sociedad y que la representación audiovisual recoge con frecuencia (Lillo Redonet, 2010). El uso categórico y repetido de la voz "héroe", en lugar de "protagonista", se ha incorporado también a la enseñanza de la escritura dramática de guiones (como herencia de la narrativa literaria) asumiendo tal intercambio como pedagogía propia (Tobias, 1999: 83 y 92).

En este trabajo se definen ambas figuras, la del protagonista y la del héroe, con la finalidad de demostrar que la distinción entre ambos conceptos es fundamental para la comprensión del sentido de las historias cinematográficas y televisivas. Por ello, el objeto de este artículo es doble: por un lado, se trata de explicar que la identificación y asimilación del héroe y el protagonista es errónea, y por otro lado, se define lo heroico como una cualidad. El uso del término "héroe" para hablar de cualquier personaje principal de las historias implica una valoración moral determinada que no todo protagonista merece. El término de protagonista hace referencia al lugar que ocupa un personaje en la acción de una historia, es decir, es una categoría funcional dentro del drama. Sin embargo, el concepto de héroe implica una valoración específica de la acción y, por ello, la categoría que representa es moral y no funcional. Aunque cabría extender también esta distinción al ámbito de la teoría literaria y, siendo estrictos, a la propia vida, el interés específico por el drama audiovisual, considerándolo como representación y no mera imitación, permite analizar los niveles de categorización que permiten distinguir al héroe del protagonista.

Estos dos niveles de categorízación de la acción constituyen la metodología apropiada para un análisis razonable de los conceptos, desde una perspectiva humanística. En primer lugar, en el artículo se considera que la primera razón por la cual no cabe identificar al héroe con el protagonista es la diferencia entre la implicación funcional de un personaje en el relato y la valoración o juicio final que se puede emitir sobre una acción realizada por representación. La función correspondería al protagonista y el juicio ético, al héroe. En segundo lugar, se demuestra por qué lo heroico es un atributo de la acción y así se recogen las características que definen lo heroico como una cualidad predicable de la acción 
dramática. En este sentido, se argumenta por qué la interpretación del relato audiovisual en clave dramática (Esslin, 1997: 9-13) permite valorar una ficción completa como una única acción y así hacer que también todos los elementos de la ficción participen del juicio sobre la acción representada. Esta calificación puede ser el heroísmo. Esto es, si se considera una ficción como una acción única, también cabe la posibilidad de interpretar el signo de su acción como heroica o no, según sus atributos ${ }^{1}$.

\section{EL PROTAGONISTA DEL RELATO Y LA FUNCIÓN ORIENTADORA DE LA ACCIÓN}

Para comprender razonablemente el itinerario conceptual del héroe y entender las causas de la asociación mencionada entre el héroe y el protagonista de una historia, en primer lugar, cabe prestar especial atención a los elementos de la dramaturgia que definen el concepto y la función del protagonista. La etimología del término protagonista puede arrojar la luz de la tradición como punto de partida de un estudio de carácter interdisciplinar en el ámbito de lo cinematográfico. Y, a la vez, pone de manifiesto cómo el surgimiento histórico del protagonista coincide con la exaltación de los primeros héroes de la literatura oral y escrita y la importancia del conflicto o agon en la dinámica interna del drama épico clásico.

Del griego "protagonistés", la palabra es el resultado de la unión de "protos", que significa primero, y de "agonistés", que significa actor. Así el protagonista es "el primero en la acción", el que más actúa (Ayuso de Vicente, 1990: 310)2: es el personaje principal del relato (Spang, 1991: 24-25; Mackee, 2002: 72, 172-176.) Además de usar el término figura para referirse al de personaje, Spang distingue a los personajes principales de los secundarios, por el número de informaciones que recibimos de ellos, la frecuencia de sus apariciones en escena y la cantidad de interacciones que mantienen con el resto de los personajes (Spang, 1991: 163-165). Como guía de la acción principal, el protagonista suele trabar alrededor de sí el resto de las acciones, en contraste con la función cooperativa de los secundarios. Es el ejecutor de la acción en el sentido funcional y la dota de sentido por "participación" activa en ella, no necesariamente por "cualificación"

\footnotetext{
${ }^{1}$ Este artículo expone una parte de la investigación desarrollada en la tesis doctoral de la autora. En ella se defiende, fundamentalmente, la comprensión del drama audiovisual como la representación de una sola acción humana, sobre la que es posible emitir un juicio de valor, sólo y exclusivamente una vez finalizado el relato. Y explica la voz heroica como una cualidad de la acción. De modo que no sólo cabe valorar a los personajes de las historias como héroes o no, sino que es posible también valorar a las ficciones como heroicas, en su caso, dado que la ficción representa, como se ha dicho, una sola y única acción. GUTIÉRREZ DELGADO, Ruth, Lo heroico en el cine de John Ford, tesis en proceso de publicación; defendida en Pamplona, el 15 de diciembre de 2004 y dirigida por el profesor dr. d. Juan José García-Noblejas Liniers.

${ }^{2}$ En concreto, la autora data la aparición del protagonista con "Tespis", pues en el teatro griego anterior sólo había un corifeo y/o jefe de coro, que es el antecedente del protagonista. Esquilo introduce el segundo personaje (deuteragonista) y Sófocles, el tercero (trigonista).
} 
46 El protagonista y el héroe: definición y análisis poético de la acción dramática

$$
y \text { de la cualidad de lo heroico }
$$

de la acción emprendida en la ficción.

De hecho, pueden darse antagonistas con el mismo peso narrativo y dramático que el protagonista (Spang, 1991: 165). Y sin embargo, no se califica como héroe al antagonista de la historia.

Es decir, la frecuencia de participación en la acción en un relato no indica necesariamente el signo ni el valor de las acciones desarrolladas en la acción: sólo indica el movimiento de la acción, no cómo sea ese movimiento. Antes bien, el juicio sobre la acción ha de estar relacionado con un espíritu particular, "un ánimo", en palabras de Choza (Choza, 1990: 70), el valor moral de la acción, según Scheler (Scheler, 2003: 32-33), y no con la mera capacidad dramática de obrar $^{3}$. En ese sentido, la acción del personaje principal es el motor de la acción completa. La función que cumple el personaje principal es participar de la acción y dinamizarla.

Ubersfeld, por su parte, señala que el personaje es en sí un lugar de confluencias de funciones (Ubersfeld, 1989: 85 y 88): "El personaje representa así, en el espacio textual, el punto de cruce o, más exactamente, de incidencia del paradigma sobre el sintagma; se trata de un lugar propiamente poético". Las acciones de los personajes ( $\mathrm{y}$, por ello, también la del protagonista) son representaciones mediadoras de las intenciones y conductas (el carácter de la historia) que se entretejen en la acción global que constituye la representación mostrada. Por otra parte, aunque Menke concede a este "mostrar" participado la categoría del hacer, previene de la ausencia de la "seriedad" del drama, un rasgo que el autor toma prestado de Schlegel, y que ambos autores definen como "la dirección de las fuerzas del alma para lograr un fin" (Menke, 2008: 153). A su vez, Menke toma el concepto de Schlegel (Schlegel, 1967: 30). Si el fin está ausente en la acción representada (y participada), tal y como defiende Menke, sólo queda mostrado el desarrollo de la acción no la acción misma, que ha necesariamente de contar con un fin para estar completa, como sostiene Aristóteles en su Poética (1449b, 24); a este respecto, cabría poner en crisis también el sentido mismo de la función que cumple la premisa de toda ficción, entendida como el prólogo o arranque de esa única acción. Pues si se sigue radicalmente la lógica de Menke sobre la ausencia del fin final en la representación, tampoco cabría sostener que la premisa indicara la intención moral de la historia. Carente del fin propio de la praxis, la representación perdería la posibilidad natural de mostrar una acción completa y de demostrar su propia constitución dramática como razonable en términos poéticos.

\section{1. La acción en el drama}

\footnotetext{
${ }^{3}$ La capacidad de obrar está asociada a la acción. Aunque no a cualquier tipo de acción: se trata de la acción humana libre que se distingue de los actos naturales biológicos porque se delibera racionalmente.
} 
La acción que realiza el protagonista en el relato varía según se trate de una narración o se represente en un drama. $Y$ en esta diferencia cabe detenerse con atención. En la tradición aristotélica, el drama, con más énfasis y distinción que la narración, se vincula a la acción práctica en la medida en que es pura representación de la praxis vital (García-Noblejas, 1982: 470-472), de hombres que obran, de la acción (Aristóteles, III, 1448b,VI, 1449b). Y en ello radica uno de los vínculos esenciales del drama con la realidad. De hecho, en la interpretación que hace Labrada sobre la estructura narrativa de la acción humana expuesta por Aristóteles en su Poética, la autora observa que en los dos modos narrativos indicados (la narración y la representación) se halla el mismo planteamiento: la felicidad o la infelicidad de una vida (Labrada, 1992: 51-53), aunque contada de manera sintética. C. S. Lewis señala esa diferencia así: "En la vida real, el dolor nunca acaba en un estallido ni en un sollozo. (...) Lo que hace el dramaturgo es seleccionar los elementos de la realidad que su arte necesita; y lo que éste necesita es lo excepcional" (Lewis, 1982: 62). Cómo dice Mamet: "It is our nature to dramatize" ( Mamet, 2000: 3) . Esa tendencia a dramatizar los aspectos de la vida real es la que genera cauces de argumentación poética -las tramas- de una ficción, sea cinematográfica o televisiva y sabiendo que, en ello, comparten la expresión representativa con el drama (Mamet, 2000: 16). En el mismo hecho de dramatizar un acontecimiento aparentemente insignificante se aportan las razones y los efectos que causa en el alma humana (Mackee, 2002, 18-19), así como las maneras de resolver la causa del drama: el conflicto, las emociones que suscita y su resolución.

No sólo la acción, sino el grado de particularidad del personaje principal (asunto que es causa de su reconocimiento) se hace más realista en el drama que en la narrativa (Spang, 1991: 160). En el drama, el personaje es encarnado por un actor: la acción cobra vida aparente, no imaginada. En definitiva, se simula que la acción es real. En ese punto es donde sitúa Esslin la conexión con la realidad personal: "Literature which is designed for reading alone is far more straightforward, far more lineal or unidemensional than drama with its multiple levels of both expression and meaning, with objectivity which puts the onus of interpretations on the recipient of the experience, the spectator" (Esslin, $1997: 110$ ).

Según Aristóteles, en ella se hace "la imitación actuando" (Aristóteles, VI, 1449b). No en vano, Armer define la acción dramática cinematográfica así: "The term action does not refer only to physical movement. (...) Narrative action often is internal, consisting of emotional or intellectual change within a character or personal decisions that alter the direction of the story" (Armer, 1988: 36-37).

Para Menke, también existe una distinción clara entre la acción representada dramáticamente y la acción narrada. Mientras que el drama busca representar

\footnotetext{
${ }^{4}$ “Está en nuestra naturaleza el dramatizar" (la traducción es mía).
} 
48 El protagonista y el héroe: definición y análisis poético de la acción dramática

$$
\text { y de la cualidad de lo heroico }
$$

la acción actuando, la narración relata la acción dirigiendo la imaginación (Aristóteles, $\mathrm{V}, 1449 \mathrm{~b})^{5}$. Menke también matiza respecto de la acción dramatizada en el teatro o en el cine: mientras que, en la representación teatral la acción se ejecuta "en el momento presente", en el cine se trata de una "representación reproducida técnicamente" (Menke, 2008: 148), que, en sentido estricto, recoge esa acción del momento presente de manera duradera. La calidad y naturaleza de esa representación de la acción reside en que "en la representación de la acción no se tiene que conseguir el fin de la acción mediante su representación sino que tiene que quedar visible la forma de la acción” (Menke, 2008: 148). Es decir, la acción no se realiza sino que se muestra, y por ello, se concluye que en la representación se dan dos acciones: la acción mostrada (la acción práctica) y la acción mostradora (la ficción). Este planteamiento considera que la acción del personaje particular (un agente, dentro del universo de ficción) se engloba dentro de la acción completa ${ }^{6}$.

\section{2. Dinámica de la acción dramatizada}

Bal considera que la preponderancia del drama sobre la narración se debe al efecto que causan los diálogos declamados (Bal, 1998: 153); al tipo de acción que ejecuta el personaje, y a la vinculación narrativa que mantiene con la acción: "(...) Un acontecimiento es transición de un estado a otro. Los actores son agentes que llevan a cabo sus acciones. No son necesariamente humanos. Actuar se define aquí como causar o experimentar un acontecimiento" (Bal, 1998: 13). Aristóteles expuso este aspecto de los personajes en la Poética, al afirmar que no es necesario que haya personajes para que haya acción, ya que no se imita (representa) a los hombres sino a las costumbres, a la vida. Sin embargo, Aristóteles llama carácter a una de las partes que componen el objeto poético y la define como el sentido volitivo, el querer implícito de la acción, la intención (Aristóteles, IV). Por ello, el personaje principal no es sino el carácter que indica el signo de la historia, el depositario del movimiento de la acción dramática. En el relato cinematográfico, las acciones de los personajes son, según García-Noblejas, "objetos primarios de la enunciación" (García-Noblejas, 1982: 466), en la medida en que constituyen el paradigma de verificación poética del relato. Sin embargo, las formas significativas que adquieren los elementos narrativos técnicos (tales como la fotografía, la banda sonora, la iluminación, la escenografía) y los poéticos (tales como la perspectiva, el montaje, el género) aportan un contenido semántico al relato (García-Noblejas, 1982: 467-468) ${ }^{7}$ y participan del sentido

\footnotetext{
${ }^{5}$ Entiéndase aquí la obra escrita para su lectura. Aristóteles distingue el tipo de imitación de la epopeya, la tragedia y la comedia, de ellas la epopeya es la que, en modo, más se parece al concepto que hemos distinguido.

${ }^{6}$ Se volverá sobre el tema de la representación más adelante.

${ }^{7}$ Se trata de la enunciación poética que puede considerarse la diégesis de la historia.
} 
completo de esa acción.

Dawson también retoma el esquema aristotélico de la fábula al explicar la naturaleza de la acción dramática. El autor recuerda que este esquema ha de tener dos características fundamentales: una cierta extensión y una estructura tripartita: el principio, el medio y el fin (Dawson, 1970: 14). Aristóteles lo expresa así: “(...) es evidente que se debe estructurar las fábulas, como en las tragedias, de manera dramática y en torno a una sola acción entera y completa, que tenga principio, partes intermedias y fin" (1459 a, 15-20). Al igual que la acción práctica, la acción dramática se constituye con el propósito inicial de emprender un movimiento que cabe entender en términos de "promesa" (Yepes, 1993: 266-271), cuyo desarrollo implica necesariamente un cambio que aparece expresado en dos acciones: la de mostrarse y la de demostrarse (Mackee, 2002: 147-148; Gutiérrez, 2009); ambos verbos coincidirían conceptualmente con las acciones aludidas por Menke: un perfeccionamiento de la acción o un acto de imperfección; y cuyo fin no puede entenderse sólo como término sino como fin final, (García-Noblejas, 1982: 228; Labrada, 1992: 57), que sí consideran "seria" a la ficción, en términos de finalidad.

Según Abirached, a modo conclusivo:

La finalidad de la representación ha sido siempre imitar las acciones de los hombres, por mediación de los actores, a través de un espacio y un tiempo figurados, ante un público invitado a dar fe a las imágenes así construidas (...) el personaje está construido de tal manera que exige pasar del campo de lo posible al universo del presente para percibir allí una calificación inmediata (Abirached, 1994: 89-90).

\section{3. Función y calificación: dos niveles de análisis dramático}

El paso al "universo del presente" sólo se da una vez conclusa la historia porque consiste en la salida del mundo posible. De modo que esa calificación del personaje sólo puede aparecer cuando el drama ha terminado, cuando la acción ha terminado. La ficción dramática plantea, no obstante, algunos problemas, si se comprende como mera imitación tanto de acciones individuales como de una única acción completa, en principio, por cuestiones de espacio, tiempo y naturaleza (Verdenius, 1949: 2-3). Se entiende que la complejidad de la mimesis praxeos se comprende a través del concepto de representación, en lo que tiene de síntesis metafórica. En ese contexto, la calificación es el signo o cualidad de la acción realizada que no necesariamente se indica ni por la función ni por el nombre del personaje, ya sea o no el personaje principal de la historia, como subraya Hegel: "El nombre indica desde luego un individuo, mas como simple nombre no lleva sin embargo a la representación (...) necesita ulteriores indicaciones para 
50 El protagonista y el héroe: definición y análisis poético de la acción dramática

$$
y \text { de la cualidad de lo heroico }
$$

alcanzar la intuición determinada" (1984: 72). Esas indicaciones pertenecen al campo de las predicaciones de una serie de rasgos de la acción. Por ello, el estudio de la acción se corresponde con el nivel dramático de análisis, y no con la valoración final sobre las acciones de los personajes y la acción completa de la historia, una vez concluida. Ambas, acción y cualidad o valor de la acción, no se oponen aunque se las pueda distinguir, como señala Ubersfeld a propósito de la crítica de Rastier a la teoría deconstruccionista: "La oposición entre acción y cualidades no tiene en lingüística, ninguna base científica (...) los inventarios de las 'cualidades' y de las 'acciones' de un actor varían correlativamente a lo largo de un relato. Aparte de que esto suponga la ruina del personaje consigo mismo, implica que (...) la oposición entre cualificaciones y funciones cesa, deja por ello de ser operativa" (Ubersfeld, 1989: 88).

La calificación inmediata que hacemos de la acción representada impone que también la acción expresada -como muestra y hecho mismo concluso- incluya una finalidad que dé sentido a toda la historia: esa finalidad se percibe como una energía o fuerza gravitatoria en el drama, un lugar hacia el que la acción ha de correr irremediablemente y que mantiene, pese a las contradicciones de los personajes e incluso frente al intervencionismo del autor, "la unidad y armonía del todo", en los términos en los que se expresa Verdenius (1949: 5).

\section{4. Drama y existencia del Mal}

Pero la armonía sólo es posible tras el caos. El principal detonador del caos en la poética audiovisual se concreta, como en cualquier drama, en el conflicto. El agon griego es precisamente eso: "el conflicto entre personajes y males representados constituye el núcleo generador de la intriga y que se manifiesta a través de la acción" (Estébanez Calderón, 1996: 882). El protagonista "nace" en un contexto conflictivo. Desde la perspectiva del sentido, el movimiento dramático no sólo pretende reconstituir radicalmente el desorden que interpela al protagonista exigiéndole actuar, sino que afecta también al resto de los personajes que habitan ese mundo creado. Así la razón del desorden se hace tan común como se comparten el cambio y el signo cualitativo de ese cambio. El conflicto salpica a la constitución de la ficción condicionando el movimiento mismo de la acción (Mackee, 2002: 138-139). Sin conflicto no hay acción y sin acción no hay cambio, sea cual sea su valor final.

Respecto de la acción narrada, Blanch lo explica así: “(...) lo que ocurre es que -desde el punto de vista del Arte- una vida tranquila y serena, sin grandes antagonismos, no suele ofrecer materia suficiente para armar sobre ella un argumento literario realmente interesante y conmovedor. Francois Mauriac solía decir que el pecado era la materia prima para una novela religiosa (Blanch, 1995: 141).

Mamet apunta esta idea al afirmar lo siguiente: "The purpose of art is to delight us: certain men and women (no smarter than you or I) whose art can delight us have been given dispensation from going out and fetching water and carrying 
wood. (...) The theather exists to deal with problems of the soul, with the mysteries of human life, not with its quotidian calamities" (2000: 26-27).

El mal que aqueja al alma humana es el catalizador dramático. Pero qué textura adquiera el mal en su versión poética atañe directamente a los lugares del itinerario dramático tales como los obstáculos y peripecias de la trama. Por ejemplo, Mamet descalifica los "dramas de Problema" en la medida en que, cuando se trata de resolver un problema, no se pone en juego la enjundia dramática de los personajes (2000: 14-22). Simplemente se para la acción, y al personaje se le supone vencedor de la contienda desde el principio de la historia. Sin embargo, hay ficciones que golpean el núcleo del drama humano porque, según Mamet, tienen "(...) something in them that comes from the heart, and, so, goes to the heart" (2000: 21). Cuando el propio Mamet señala que por naturaleza todos tendemos a dramatizar, explica que la realidad circundante nos afecta emocionalmente o tiene un impacto en la persona que condiciona la visión que de las cosas tiene afectándolas de sus propios sentimientos (2000: 3); la expresión dramática expresa esa relación esencial con el mundo, en especial, con el mundo de las personas.

Pero el modo de presentar el movimiento "del mundo de las personas" es hacerlo progresivo. Por ello, el personaje heroico no puede presentarse como tal desde el principio de la historia. Según Greimas, el "héroe" del relato mítico (diremos mejor que el personaje principal) puede adquirir ciertas cualidades durante la trama que le ayudarán a salir victorioso de las dificultades (1974: 81-83). Greimas presupone de antemano que el protagonista es un héroe y no un personaje con posibilidades. Por otro lado, Greimas considera que esas cualidades adquiridas a lo largo de la acción no son la razón de su heroísmo. En todo caso, la supuesta calificación que obtiene el personaje al final de la historia no es sino un signo del vencimiento o no de unas fuerzas dramáticas que se oponen a su estado primigenio (Greimas, 1974: 8). Según Scholes, ese opositor dramático podría tratarse de un "antagonista cósmico" al que vencer (1968: 15-17). De ahí que Labrada se pregunte si es posible asimilar la "felicidad dramática" con el heroísmo (1992: 48-49).

Greimas propone dos modelos de "héroes": el derrotado y el victorioso. Mientras que el primero sufre una pérdida de capacidades, el segundo, además de ser motor de la acción, gana y mejora a lo largo de ella, adquiriendo nuevas cualidades. Parece que en esta propuesta resulta indiferente el recorrido dramático que haga el protagonista pues se le presupone "héroe" desde el inicio. Pero en el nivel funcional, los obstáculos no garantizan el signo de la acción: tan sólo la permiten, posibilitan el drama, es decir, que surja la acción. Para Bal, sin embargo, los "procesos de mejoría" o de "deterioro" narrativo, tomados originariamente de Bremond, cambian el valor de la empresa terminada al final de la historia. Y por ello la calificación de la acción de los personajes también cambia.

Si la calificación de la acción del protagonista sólo se obtiene una vez terminada y finalizada la acción, el rango de heroico no puede atribuirse al personaje 
52 El protagonista y el héroe: definición y análisis poético de la acción dramática

$$
y \text { de la cualidad de lo heroico }
$$

desde el principio de la historia, ni todo protagonista es, necesariamente, el héroe del drama.

\section{EL ORIGEN DEL HÉROE}

La teoría del guión se ha hecho eco de esa particularidad de la acción del protagonista y ha llamado héroe al personaje principal, admitiendo como rasgos de valor los elementos del itinerario dramático, esto es, la estructura del relato. No obstante, al hablar del héroe en el cine, se han elaborado tipologías heroicas y se han introducido ciertos matices para distinguir al héroe ejemplar del que no lo es (Sánchez-Escalonilla, 2002: 96-97). Con lo cual, se pone de manifiesto, en primer lugar, que existe una contradicción en el uso del término que lo hace tan plástico como impropio; en segundo lugar, cabe atribuir diferentes cualidades a los personajes por las que se distinguen los unos de los otros, además de por los rasgos de carácter; y que el concepto de héroe no puede acoger ambas distinciones, la del ser ejemplar y la del que no lo es.

Por otro lado, quizá sirva de explicación primordial el hecho de que es propio del drama que la acción sea dinámica y no estática. De modo que, a medida que avanza la acción, el protagonista pueda transformarse, empeorando o mejorando su conducta. Es lo que Sánchez-Escalonilla, entre otros, explica como proceso de metamorfosis del "héroe" que se encarna en el arco de transformación del personaje (2002: 81-82). Para Sánchez-Escalonilla, las vivencias que puede tener el "héroe" en su viaje (Purificación, Madurez, Superación del trauma, y Descubrimiento) indican una motivación interior distinta (2002: 82). Si esto es así, cabe calificar de distinta forma a los protagonistas de las historias. De ahí que la formalización de la acción heroica hecha por Greimas no se ajuste a los términos de calificación y cualificación que pide cualquier acción. Pues como subraya Eco, citando a santo Tomás de Aquino: "conocemos nuestras humanas potencialidades espirituales <<ex ipsorum actuum qualitate>>, a través de la cualidad de las acciones de las que ellas son origen" (1992: 299-300).

\section{1 La lectura cultural}

Además de la identificación entre la función del protagonista, como el personaje que más actúa, y el héroe, otra de las razones de la asimilación de ambos conceptos es la lectura cultural que se ha hecho sobre el héroe. En esencia, esta lectura tiende a equiparar por igual a los personajes emblemáticos de cada momento histórico, figuras que parecen catalizar las preferencias morales de una cultura particular. Pero, lo que manifiesta cada cultura es distinto y, en ese sentido, el intento por definir al héroe según el paradigma cultural resulta infructuoso. La rica discusión sobre este asunto se divide en dos interpretaciones: por un lado, algunos autores consideran heroicos a todos los personajes que representan los valores vigentes en una sociedad, generando una tipología de lo heroico que tiende al infinito. No consideran que exista un concepto de lo heroico con vocación universal. Y por otro lado, están los autores que, además 
de considerar relevante el aspecto cultural del heroísmo, entienden que existen rasgos unívocos del heroísmo.

El principal objeto de este apartado es demostrar que no podemos hacer depender la definición del heroísmo de las eventualidades culturales y sociales que, como tales, son fenomenológicas. Cada cultura vive y dramatiza según su horizonte de expectativas. Pero la cualidad de lo heroico no es un término vacilante.

Dúmezil piensa que los héroes surgen y se retratan en el origen de toda cultura, como los activos protagonistas de la construcción de los pueblos (1996: 7-13). La protección sagrada de estos actores privilegiados parece transferirse también en el discurso que recoge las gestas heroicas, convirtiéndolas así, en mitos: relatos sagrados sobre el origen. Para Scholes y Kellog, el mito es un tema tradicional de carácter narrativo (1966: 12). Kirk discute que el origen del mito sea la gesta heroica admitiendo que es la psique humana la que motiva esas consignas morales sobre la acción, en la línea planteada por Freud y Jung (Kirk, 1992: 14). Según esto, los modelos de conducta que presenta cualquier sociedad son culturales, cambiantes y dependen, en gran medida, de las modas (Villegas, 1973: 50-61).

Según Aguirre, "para que aparezca el héroe la sociedad ha de tener un grado de cohesión suficiente como para que existan unos valores reconocidos y comunes" (1996: 1). En esta línea, el héroe es el catalizador moral de la cultura y de la opinión pública; constituye el máximo exponente de los ideales compartidos o aceptados en el seno de una sociedad. En un sentido más general, Gabás estrecha esa relación entre la cultura y los modelos que transmite, recordando que "cada tiempo tiene sus dogmas, mitos o sentimientos dominantes, que tratan líneas inconfundibles en la cara de la vida y del arte" (1984: 13). Desde esta óptica, la comprensión del heroísmo pasa inevitablemente por la comprensión de la cuna cultural a la que se vincula su origen: su apertura comunicativa es menor. En ese sentido, cabe afirmar que cada cultura tiene sus "héroes".

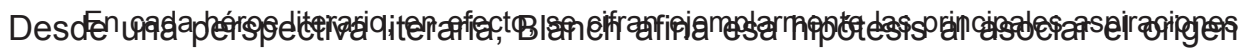

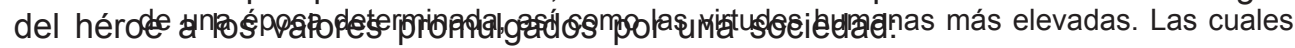
suelen representarse no en abstracto sino en acciones concretas, es decir, el esforzado empeño con que el personaje intenta salir airoso de una serie de aventuras, erizadas de dificultades, pero que le permiten mostrar sus talentos y su excelencia moral, más todavía que su fuerza física (1995: 73).

Puede observarse que, pese a que el héroe aparece asociado a cada cultura, Blanch también afirma el carácter esforzado de la acción heroica, como una característica necesaria y universal del heroísmo. Rasgo que no tiene por qué ser seña de identidad de toda cultura. Según la definición de Blanch, lo que cambia es el trayecto que ha de recorrer el personaje para sobreponerse a las 
54 El protagonista y el héroe: definición y análisis poético de la acción dramática

$$
y \text { de la cualidad de lo heroico }
$$

circunstancias o demostrar su fortaleza. Cambia el modo, pero, en esencia, lo que se pone en juego es la posibilidad de ser fuerte. Esta definición no encaja de entrada con algunos modelos a los que se les ha denominado héroes tales como el héroe romántico, cuyo patetismo y derrotismo desconecta de toda acción esforzada para abandonarse a la pasividad suicida, rasgo que comparten los seis tipos de héroes románticos definidos por Argullol (1999, 273-323) ${ }^{8}$ o el héroe desencantado, el anulado, el antiheroico (Blanch, 1995: 82 y 110) o el encapsulado (Argullol \& Trías, 1991: 53) del que gran parte de la cinematografía se hizo eco tras la aparición del antihéroe del cine negro o el héroe crepuscular del western (González, 2007).

Respecto del análisis cultural, Banús introduce un rasgo suprahistórico nada desdeñable para la comprensión del heroísmo. El autor entiende:

Caben dos posibilidades: o bien que la literatura clásica exprese la idea de héroe que 'todos llevamos dentro', es decir, sea la realización perfecta de una vivencia antropológica o bien que, a partir de la literatura clásica, nuestra visión del héroe sea la que es: es decir los héroes nos parecen héroes porque corresponden con la imagen que ha dejado en nosotros la transmisión de unos héroes concretos, los clásicos (Banús, 2000: 283).

Banús argumenta que existen similitudes entre héroes surgidos en narrativas exentas de las influencias de los clásicos greco-romanos que podrían sostener la hipótesis sobre un contenido antropológico universal (2000: 283). De modo que parece plausible plantear la búsqueda de un concepto de héroe ajeno a la voluntad cultural de un pueblo. Por otro lado, también cabe afirmar que los modelos clásicos se han perpetuado en la memoria colectiva a través incluso del cine (Lillo Redonet, 2010).

La lectura cultural conduce a una indefinición del heroísmo, pues lo hace presa del signo de los tiempos. Al hablar del antihéroe, Lipovtesky explica que es fruto del efecto de la desdramatización del mundo, que se traduce en no tomar en serio la realidad (Lipovstesky, 1986: 136-142). El héroe que surge ahí "se caracteriza por una actitud maliciosamente relajada frente a los acontecimientos" que le rodean que le lleva a no implicarse en sus acciones (Lipovstesky, 1986: 142). Esa pasividad en el obrar (Argullol, \& Trías, 1992: 52-53) refleja cómo ese neohéroe transgrede la norma básica de la acción dramática del protagonista: la de actuar en la historia y no, la de padecerla.

Por ello, ante este panorama, Savater concluye que el heroísmo es imposible. Pues para el autor, desde la Modernidad, "el héroe" va acumulando sarcasmos y recelos de su fracaso inevitable (Savater, 1982: 132). Si el concepto fracasa es porque, al menos Savater, le otorga un contenido permanente que otros autores le niegan, tal como los rasgos del héroe griego, según Savater: "el valor,

${ }^{8}$ El suicidio es el resultado de una pasión que busca hacer inoperante al actor para siempre. La lesión sufrida a causa de esa pasión impide el crecimiento propio de la acción moral que en este caso acaba en la muerte. 
la generosidad, la independencia, la creación, la liberación, el triunfo, el fracaso, el orgullo y la dignidad" (1982: 135).

\section{2. El viaje del héroe o la lectura dramática de la acción heroica}

Decía Reyes que los rasgos que hacen popular al héroe son su condición de "desdichado viajero y de guerrero" (1965: 28). Quizá por ello algunos autores como Campbell y Miller han recuperado el esquema del viaje del héroe épico, para explicar la continuidad de las formas heroicas y, en el caso de Campbell (1968), aportarles una interpretación psicoanalítica ${ }^{9}$. Como resultado de esa traducción a un esquema o viaje del héroe, apoyado en lo griego, también el recorrido se hace funcional o, dicho de otro modo, se vacía del contenido simbólico que tenía en la tradición de donde surge con el propósito explícito de subrayar los hitos universales de la acción heroica. El diseño de la estructura de la acción modélica del héroe (Villegas, 1973: 61) prescinde de la valoración moral o cuenta con las particularidades culturales del modelo llegando a una contradicción in terminis.

Con ello se plantea la contradicción de querer prescindir y a la vez contar simultáneamente con la lectura cultural y la funcional en la descripción del paradigma heroico y de su viaje narrativo. Las siguientes palabras de Villegas son un ejemplo más de la problemática que genera el intento por catalogar los rasgos del héroe, convertido en un "cajón de sastre":

En la teoría cinematográfica se han adoptado dos modelos heroicos fundamentalmente: el de Joseph Campbell y el de Northrop Frye. La principal diferencia entre ambos radica, según Wack, en que mientras Campbell aboga por un viaje heroico cultural sin la componente mítica, Frye convierte en arquetipo mítico al héroe, lo abre a la posibilidad de conciliar las expectativas humanas universales y lo específico cultural. Para ello, Frye (2004) establece una identificación entre el paso natural de la vida expresado en las estaciones y los arquetipos de los géneros narrativos. En cada uno de ellos, el héroe atraviesa etapas arquetípicas del ciclo heroico (Wack, 2010: 1-13). El paso por estas etapas de la vida heroica expresa bien la frágil sujeción de la cualidad heroica a la función del protagonista, pues depende más de un esquema cósmico que de la acción individual de un personaje, aunque el modelo denomine héroe a los cuatro protagonistas.

En un sentido más irónico del cine, para Mamet, "the theater is about the

El problema que persiste y de mayor valor es cuestionar las características del personaje y establecer los rasgos más o menos definitorios para los héroes respectivos de una variedad de épocas, lo cual ha sido hecho por historiadores de la literatura, muchas veces sin pensar en el concepto de héroe (1973: 64).

\footnotetext{
${ }^{9}$ Miller también menciona los trabajos de J. G. Frazer, The Golden Bough: A study of Magic and Religion; de F. R. Somerset, The Hero; de R. B. Onians, The Origins of European Though y de Otto Ranks, The Myth of the Birth of the Hero, como obras referenciales en esta línea.
} 
56 El protagonista y el héroe: definición y análisis poético de la acción dramática

$$
y \text { de la cualidad de lo heroico }
$$

hero journey, the hero and the heroine are those people who do not give in to temptation. The hero story is about a person undergoing a test that he or she didn't choose" (2000: 16). Ese modelo excluiría una amplia tipología, en la que se incluyen los héroes trágicos griegos que se definen principalmente por caer presa de la tentación y no demostrar su fortaleza heroica, superior en situaciones donde la trama pide explicitar el crecimiento del personaje, o los "héroes" románticos, cuya apatía es antidramática. El viaje del héroe de Mamet es limitado, pese a que intenta dar una definición de la voz heroica. Por otro lado, el mayor grado de simplicidad del viaje heroico se plantea en la visión estructuralista de Greimas y Campbell, para los que ser héroe consiste en atravesar una serie de pruebas y salir victorioso o no de ellas. En este sencillo paradigma la unidad de acción no implica necesariamente al resto del cosmos dramático.

Por último, cabe mencionar el viaje del héroe analizado por Vogler. El autor distingue y desarrolla doce etapas en el viaje heroico que coinciden con los tres actos de una acción dramática. El viaje del héroe de Vogler es un buen punto de partida para distinguir las etapas de una acción dramática completa, por su visión integradora de la misión heroica. Ahora bien, como estructura no resuelve la cuestión acerca del aspecto cualitativo de esa acción heroica.

\section{3. En busca de arquetipos heroicos}

Ante el aparente "trucaje" de la narrativa (que no ofrece definiciones rigurosas sobre la virtud, sino ejemplos variados y estructuras estables de la acción dramática), Savater se cuestiona cuál puede ser la ilusión que ofrezca la ética en la ficción. Banús, por su parte, propone dos arquetipos, el de Ulises y el de Antígona como modelos prescriptivos (2000: 238); pero Savater recurre a un modelo ambivalente que, alejado de los dogmas, recoge la vileza y la grandeza humanas en una paradoja enigmática: "la confianza en que la acción humana está abierta a lo posible tanto como condicionada por lo necesario" (1982: 112 y 114). Esa condición humana revelada en el heroísmo es, según Savater, la irónica superioridad del Héroe: "Héroe es quien logra ejemplificar con su acción la virtud como fuerza y excelencia” (1982: 111). Sin embargo, la virtud heroica definida por Savater parece conducir al descalabro, pues mantiene una complicidad fúnebre con la muerte, destino al que Savater no adjudica un verdadero triunfo (1982: 112-113). Pues como Hegel, también Savater contempla el heroísmo como efecto supremo de la autonomía moral, haya victoria o derrota en la lucha. Por ello, Hegel es capaz de ofrecer ejemplos de "héroes" carentes de ejemplaridad, paradigmas de "perfecta fuerza y energía" (1984: 145-146). Estos paradigmas de la voluntad física que destruyen el orbe contrastan con el paradigma completo de héroe, ilustrado por Torres-Guerra, quien señala en el héroe homérico la excelencia en la palabra (1998: 39-43). Acción testimonial y palabra no pueden contradecirse en la excelencia heroica, como también dice Arendt, al explicar que el mérito heroico radica en su voluntad de actuar y hablar personalmente (1993: 210). 


\section{4. El concepto de lo heroico}

En el núcleo de la identificación entre los dos conceptos está la estructura de la acción dramática sin duda. Esslin, que ha captado la naturaleza del drama no sólo en el teatro sino en todos los medios de comunicación, incluido el cine, como un modo de comunicación dramático, entiende que el drama es la representación del comportamiento humano (1997: 14). Así la acción, que es lo característico del drama, según Esslin y no sólo una "forma de literatura", remite a cómo es la fisionomía del alma humana, fuente de la acción. Para Frye, como he explicado, esa fisionomía es en cierto modo mítica. Pero el drama no garantiza que esa representación del alma humana sea siempre verídica, en términos poéticos, y de la misma manera.

Entonces cabe preguntarse con Pieper qué es "el verdadero heroísmo" (1980: 180-188). Tras un repaso exhaustivo por los distintos modelos heroicos que ha generado la historia de la literatura, Pieper concluye dos asuntos: el primero es que la cuestión heroica se ha considerado tradicionalmente una cuestión moral de máximos; y el segundo es que "el núcleo del verdadero heroísmo es la virtud de la fortaleza" (1980: 181). La pregunta central se refiere a la cualidad o conjunto de cualidades que hacen al protagonista héroe del drama. Por "cualidad" ha de entenderse el concepto de "categoría", según Aristóteles, a saber: "aquello por lo que algo se dice tal o cual" (Sánchez, 2000: 44), como una clase de valoración que explica la razón de porqué se expresa un juicio.

Para Pieper, se trata de la cualidad del fuerte y lo define así: "Ser fuerte es, en el fondo, estar dispuesto a morir. O dicho con más exactitud: estar dispuesto a caer, si por caer entendemos morir en el combate" (1968: 201). La fortaleza es la "resistencia en el bien" y, a ojos de Sto. Tomás de Aquino, sólo es verdadera si se alía con la virtud sobrenatural de la esperanza (Aranguren, 2000: 158; Tomás de Aquino: 2-2 q. 123 a3). Esta condición resuelve bien algunos problemas que pueden surgir, según la causa del heroísmo. Pues con tan sólo estar dispuesto a morir cabe caer en el fanatismo o en la temeridad. Ambas consecuencias son acciones desmesuradas, arrogantes y sin sentido: no son virtudes en el sentido aristotélico del término. Guitton, por su parte, asemeja al héroe con el santo y el genio en una cualidad cuyo cometido consiste en recuperar la facultad poética para que nuestra vida ordinaria cobre valor eterno: "El genio, el héroe y el santo, cada uno a su manera, está bañado por el misterio de la vida cotidiana y sublime. El genio, el héroe y el santo, cada uno a su manera, tiene una experiencia de la vida, única en su género, en lo que ésta tiene a la vez -lo repito- de banal, de familiar, de divino y de sublime" (1996: 13).

Esa búsqueda de transcendencia en todos los aspectos de la vida como consecuencia y no finalidad en sí misma de la acción coincide con el planteamiento apuntado por Moro. La excelencia, dicen Guitton, Aquino y Moro, no se bate sólo en situaciones extraordinarias y espectaculares. El fuerte, según Moro, no sólo se 
58 El protagonista y el héroe: definición y análisis poético de la acción dramática

$$
y \text { de la cualidad de lo heroico }
$$

mantiene firme ante "los peligros de muerte sino contra los que amenazan en la lucha particular" (1998: 69-73 y 88), que es donde puede darse la muerte espiritual. El riesgo que comporta "estar dispuesto a morir" trae de nuevo a colación la necesidad de que la acción emprendida en el drama cuente con las tres partes básicas de toda acción dramática y que esa acción tenga cariz moral, como la acción práctica real, según Aristóteles en su Ética a Nicómaco (2009, 113 a-115 a).

\section{CONCLUSIONES}

Aunque la caracterización del protagonista permite matizar aspectos narrativos de la acción principal y afecta a la especificación del género de ficción, en sentido estricto, el protagonista sólo se define por su función. Es decir, el protagonista es el personaje que más actúa en el relato, pero el valor de la acción no está definido en la función necesariamente.

El héroe se define por una cualidad que sólo se puede saber al final de la historia, por el sentido de la historia. Esa cualidad es universal y la forma que toma es cultural. De modo que los rasgos del heroísmo son semejantes aunque la forma (el cómo) que adoptan en la acción sean culturales.

Los viajes heroicos son ciclos que no definen el concepto de héroe, pues además de partir de la base errónea de que el personaje es heroico desde el comienzo de la historia, proponen una estructura que no necesariamente dota de cualidad heroica al protagonista antes bien delimitan las etapas esenciales de la misión sin contenido expreso.

Lo propio del héroe es la virtud de la fortaleza cuya acción principal consiste en estar dispuesto a morir. La virtud de la fortaleza ha de ir acompañada de una prudencia desinteresada por la cual se evita el fanatismo y la temeridad en la acción.

Por lo tanto, si, como se ha indicado, la calificación de la acción sólo se obtiene al final de la historia, la cualidad de lo heroico no puede atribuirse al personaje desde el principio, ni todo protagonista es necesariamente el héroe de la historia, porque el héroe es el que actúa con fortaleza y desinterés, y el protagonista es el que más actúa. 


\section{REFERENCIAS BIBLIOGRÁFICAS}

ABIRACHED, R. (1994): La crisis del personaje en el teatro moderno. Madrid: Asociación de directores de escena en España, ISBN 84-87591-35-3.

AGUIRRE, J. M.: "Héroe y sociedad: el tema del individuo superior en la literatura decimonónica”, Espéculo, Revista Electrónica cuatrimestral [en línea], número 3, junio de 1996, [Consulta: 2 de enero de 2012]. <www.ucm.es/info/especulo/numero3/heroe.htm>

ARANGUREN, J. (2000): Resistir en el bien. Razones de la virtud de la fortaleza en Santo Tomás de Aquino. Barañain: EUNSA, ISBN 84-313-1763-9.

ARENDT, H. (1993): La condición humana. Barcelona: Paidós, ISBN 847509855X.

ARGULLOL, R. \& TRÍAS, E. (1992): El cansancio de Occidente. Barcelona: Destino, ISBN 84-233-2253-X.

ARGULLOL, R. (1999): El héroe y el único. El espíritu trágico del Romanticismo. Madrid: Taurus, ISBN 9788496834323.

AYUSO DE VICENTE, M. V. (1990): Diccionario de términos literarios. Madrid: Akal, ISBN 84-7600-533-4.

ARISTÓTELES (2009): Ética a Nicómaco. Madrid: Tecnos, ISBN 9788430948154.

-(2004): Poética. Madrid: Alianza Editorial, ISBN 84-206-5809-X.

-(1974): Poética. Madrid: Gredos, ISBN 84-249-1200-4.

ARMER, A. A. (1988): Writing the Screenplay: TV and Film. Nothridge: California State University, ISBN 0-534-08292-0.

BAL, M. (1988): Teoría de la narrativa. Una introducción a la narratología. Madrid: Cátedra, ISBN 84-376-0504-0.

BANÚS, E. (2000): Literatura europea. Una introducción. Mutilva baja: New Book Ediciones, ISBN 84-896487-51.

BASALLO, A. (2000): 2001: la odisea del cine. Madrid: Espasa, ISBN 84-239-6635-6.

BLANCH, A. (1995): El hombre imaginario. Una antropología literaria. $3^{a}$ edición. Madrid: PPC, ISBN 84-288-1278-0.

BARTHES, R. (1974): Análisis estructural del relato. Buenos Aires: Editorial Tiempo Contemporáneo.

BOORSTIN, D. J. (1987): The image: a guide to pseudo events in America. New York: Atheneum, ISBN 0-689-70280-9.

BOWRA, C. M. (1964): Ancient Greek Literature. London: Oxford university Press. 
60 El protagonista y el héroe: definición y análisis poético de la acción dramática $y$ de la cualidad de lo heroico

CAMPBELL, J. (1968): The hero with a Thousands Faces. Princeton: Bollingen Series. CHOZA, J. (1990): Ulises, un arquetipo de la existencia humana. Madrid: Rialp, ISBN 84-344-1147-4.

DAWSON, S. W. (1970): Drama and the Dramatic. Norfolk: Methuen \& Co. Ltd., ISBN 416-17270-9.

DUMÉZIL, G. (1996): Mito y epopeya, II. Tipos indoeuropeos: un héroe, un brujo, un rey. México: Fondo de Cultura Económica, ISBN 968-16-4356-9.

ECO, U. (1992): Los límites de la interpretación. Barcelona: Editorial Lumen, ISBN 84264-1214-9.

ESSLIN, M. (1997): An Anatomy of Drama. New York: Hill and Wang.

ESTÉBANEZ CALDERÓN, D. (1996): Diccionario de términos literarios. Madrid: Alianza Editorial, ISBN 84-206-5251-2.

FRYE, N. (2004): Biblical and Classical Myths. The Mythological framework of Western culture. Toronto: University of Toronto Press, ISBN 0802086950.

GABÁS, R. (1984): Estética. El arte como fundamento de la sociedad. Barcelona: Editorial Humanitas.

GARCÍA-NOBLEJAS, J. J. (1982): Poética del texto audiovisual. Pamplona: EUNSA, ISBN 84-313-0791-9.

GONZÁLEZ, J. F. (2007): El héroe del western crepuscular. Madrid: Editorial Fundamentos, ISBN 978-84-245-1133-3.

GUITTON, J. (1995): El héroe, el genio y el santo. Madrid: Universidad Complutense, Club de debate, ISBN 8489365482.

GUTIÉRREZ DELGADO, R. (2009): "Mimesis praxeos or the representation of the only action: a revision of the concept from a point of view of cinematographic poetics", comunicación presentada en Re-Thinking Screenwriting. Poetics of Screenplay. New Interpretations of Aristotelian dramaturgy, Helsinki.

-(2005): Lo heroico en el cine de John Ford. Tesis doctoral en proceso de publicación, Universidad de Navarra.

HEGEL, G. W. F. (1984): Estética IV. La forma del arte clásico. Buenos Aires: Siglo XX. KIRK, G. S. (1992): La naturaleza de los mitos griegos. Barcelona: Editorial Labor, ISBN 84-7178-880-2.

LABRADA, M. A. (1992): Sobre la razón poética. Pamplona: EUNSA, ISBN 84-313-1163-0. LASSO DE LA VEGA, J. S. (1962): Héroe griego y santo cristiano. La Laguna: Universidad de la Laguna: Aula de Humanidades. 
LEWIS, C. S. (1982): Crítica literaria: un experimento. Barcelona: Bosch, ISBN 84-8585510-8.

LILLO REDONET, F. (2010): Héroes de Grecia y Roma en la pantalla. Campillo Nevado: Ediciones Evohé, ISBN 9788493742935.

LIPOVSTESKY, G. (1986): La era del vacío. Barcelona: Anagrama, ISBN 84-339-0083-8. MACKEE, R. (2002): El guión: sustancia, estructura, estilo y principios de la escritura de guiones. Barcelona: Alba, ISBN 84-8428-168-X.

MAMET, D. (2000): 3 Uses of Knife. On the Nature and Purpose of Drama. New York: Vintage Books, ISBN 037570423x.

MENKE, C. (2008): La actualidad de la tragedia. Ensayo sobre juicio y representación. Madrid: La balsa de la Medusa, 165, ISBN 9788477746867.

NAGY, G. (2001): Greek Literature, New York: Routlegde, ISBN 081532.

PIEPER, J. (1968): Justicia y fortaleza, Madrid: Rialp.

- (1980): La fe ante el reto de la cultura contemporánea, Madrid: Rialp, ISBN 8432132942.

REYES, A. (1965): Obras completas de Alfonso Reyes, 17. Los héroes. Junta de sombras, México: Fondo de Cultura Económica.

ROSE, H. J. (1960): Gods and Heroes of the Greeks: An Introduction to Greek Mythology, New York: Meridian Books.

SÁNCHEZ-ESCALONILLA, A. (2002) Guión de aventuras y forja del héroe, Barcelona: Ariel, ISBN 8434468085.

SÁNCHEZ, E.: "La esencia del hábito según Tomás de Aquino y Aristóteles". Cuadernos de Anuario filosófico. Pamplona (2000).

SAVATER, F. (1982): La tarea del héroe, Madrid: Taurus, ISBN 84-306-1199-1.

SCHELER, M. (2003): Gramática de los sentimientos. Lo emocional como fundamento de la ética, Barcelona: Crítica, ISBN 84-8432-415-x.

SCHOLES, R. \& KELLOG, R. (1966): The Nature of Narrative, London: Oxford University Press.

SPANG, K. (1991): Teoría del drama, Pamplona: EUNSA, ISBN 84-313-1136-3.

TOBIAS, R. B. (1999): El guión y la trama. Fundamentos de la escritura dramática audiovisual, Madrid: Yumelia Textos, ISBN 84-89893-61-6.

TOMÁS DE AQUINO (1957): Suma Teológica. Madrid: Biblioteca de Autores cristianos.

TOMÁS MORO (1998): Diálogo de la fortaleza contra la tribulación, Madrid: Rialp, ISBN 8432124613. 
62 El protagonista y el héroe: definición y análisis poético de la acción dramática

$$
y \text { de la cualidad de lo heroico }
$$

TORRES-GUERRA, J.: El héroe como orador. En LÓPEZ EIRE, A. (1998), Retórica, política e ideología: desde la Antigüedad hasta nuestros días, Actas del II Congreso Internacional, Salamanca, 1998, ISBN 84-930218-1-4.

UBERSFELD, A. (1989): Semiótica del teatro, Madrid: Cátedra, ISBN 84-376-0876-7.

VERDENIUS, W. J. (1949): Mimesis. Plato's Doctrine of Artistic Imitation and its Meaning to us, Leiden: E. J. Brill.

VILLEGAS, J. (1973): La estructura mítica del héroe en la novela del siglo XX, Barcelona: Planeta, ISBN 84-320-7626-0.

VOGLER, C. (1998): The Writer's Journey. Mythic Structures Writers, Stoneham: Michael Wiese Productions, ISBN 0-941188-70-1.

WACK, G.: "The Archetypal Hero Quest Myth and Northrop Frye", Academia.edu, (May 5th 2010), pp. 1-13.

YEPES, R. (1993): La doctrina del acto en Aristóteles, Barañain: EUNSA, ISBN 84-3131231-9.

\section{Breve semblanza de la autora}

Ruth Gutiérrez Delgado dedica su investigación desde hace trece años a la poética y retórica de la ficción, y en especial a la representación del heroísmo y de la identidad. Su tesis doctoral trató sobre lo heroico en el cine de John Ford. Imparte Epistemología de la Comunicación y Guión de Ficción Televisiva en el Grado de Comunicación Audiovisual de la Facultad de Comunicación de la Universidad de Navarra. Es miembro del grupo de Investigación Cultura Emocional e Identidad (CEMID) y del proyecto ministerial sobre el mito de El Quijote en la Europa del Este.

(Recibido el 25-05-2011; aceptado el 10-01-2012) 